\title{
Hydrodynamic system behaviour: its analysis and implications for flood risk management
}

\author{
Karin M. de Bruijn ${ }^{1, a}$, Ferdinand L.M. Diermanse ${ }^{1}$, Marcel van der Doef ${ }^{1}$, Frans Klijn ${ }^{1,2}$ \\ ${ }^{1}$ Deltares, Flood Risk Management department, Boussinesqweg 1, 2629 HV Delft, The Netherlands \\ ${ }^{2}$ Delft University of Technology, Delft, The Netherlands
}

\begin{abstract}
Knowledge on the different components of flood risk has much improved over the last decades, but research which fully takes into account not only the interactions between those components but also between different areas in a catchment or delta is still rare. Integrated analyses based on a complete system's approach at sufficiently large scale will improve our understanding of how flood risk systems with flood protection infrastructure in place behave under extreme conditions, it may help to develop sensible long-term strategies, and allows us to better prepare for flood events of all magnitudes. To illustrate the relevance of a hydrodynamic system's approach for flood risk management we analyse the effect of defence breaches on flood risks elsewhere along the lower Rhine River and discuss the use of this knowledge for flood risk management.
\end{abstract}

\section{Introduction}

In the past, flood risk management was often reactive and measures were taken to prevent the latest event from happening again. Currently, many countries adopt a proactive flood risk management approach. In such an approach strategies and measures are based on thorough flood risk analyses.

Often, such flood risk analyses are carried out in order to evaluate local measures or to assess the economically optimal flood protection standard of a location or a small area $[1,2]$. However, in river areas with a flood protection infrastructure in place, the failure probabilities of different locations are often interrelated. Strengthening one embankment will, for example, influence the failure probability of the embankment on the opposite bank and downstream.

Local risk analyses may provide incorrect answers if these interdependencies are not considered [3, 4]. If regional risk maps are derived from a mosaic of local risk calculations, the risk outcomes may be in contradiction with physical laws or river behaviour.

Next to local flood risk analyses, there is thus also a need for regional risk assessments in order to assess the effects of high discharges in larger rivers on a countrylevel or in a basin, instead of on one village or on one embankment section and to develop better flood risk management strategies for the system as a whole. To derive consistent regional strategies it is insufficient to just combine local measures since the combination of local plans is not necessarily the optimal plan for the system as a whole. Local measures may counteract each other and local analyses may not result in measures that serve a large part of the system, such as floodways or detention areas.

Not only the system's flood risk, but also related aspects such as the number of potential breaches along the river per event, the extent of the flooded areas, the number of potentially affected persons in one event and the total damage in all areas combined is relevant knowledge, for example in order to:

\footnotetext{
${ }^{\mathrm{a}}$ Corresponding author: Karin.debruijn@deltares.nl
}

- $\quad$ assess the need for reinsurance or (re-) assessment of the insurance possibilities;

- $\quad$ evaluate the societal disruption and possibilities for recovery;

- consider the need for coordination and collaboration between areas and communities in the preparation of emergency plans.

For assessing flood risks at regional scale, hydrodynamic interaction between different locations must be taken into account. Hydrodynamic interaction is defined as the decrease of water levels due to breaches elsewhere in the river protection system. This lowering of water levels may have a significant effect on the failure probabilities of other locations and thus influences flood risks of the system as a whole [3]. Examples of the Mississippi [5] and Po River [6] where (intentional) breaches lowered water levels and prevented the flooding of downstream urban areas show the significance of hydrodynamic interaction.

The effect of a breach in an embankment along a river on the failure probabilities of other embankments depends on:

- The volume of water flowing through the breach compared to the volume of water in the river;

- The location of the breach (upstream, downstream, opposite side of the river);

- The moment of breaching: If the peak discharge is lowered due to the breach, the effect on other areas is generally larger than if a breach occurs after the peak of the river flood has passed.

The breach flow depends on the hydraulic head, the breach growth rate and final size, the moment of breaching (before, at or after the peak of the river flood wave) and the storage volume of the area behind the embankment.

In some cases, water flowing through a breach out of the river into the protected floodplain area, may flow back into the river at a downstream location or into 
another river or river branch. In such cases the breach may increase the flood probabilities of the areas located along the other branch or river. Since such situations are rare, we focus on the positive effects in this paper only. For a description and analysis of these negative effects, consider [7].

The effect of hydrodynamic interdependencies on flood risks in a river system with protection depends on:

- Differences in protection standards/ failure probabilities between locations in the system;

- The most relevant failure mechanisms (which influence the moment of breaching)

- The storage capacity of the areas protected by the embankments in relation to the shape and volume of the discharge wave;

- Flood impacts and differences in impacts in the areas behind the breaches.

If differences in the strengths of embankments are small, it is totally unpredictable which embankment will fail first. Multiple breaches may occur at the same time and the effect of hydrodynamic interdependencies on flood probabilities is relatively small. However, if differences in strengths are larger, the failure probabilities will differ even more than the strengths do, due to hydrodynamic interdependencies. The failure probabilities of the strongest embankments are reduced by the flooding of the weaker sections.

The failure mechanism may also be relevant, since it influences the moment of failure. In areas where embankments are likely to fail due to piping, failure may occur after the peak has passed. In such cases the effect on downstream areas is smaller than if the embankments are more likely to fail due to overtopping which occurs before or at the peak of the river flood wave.

The storage capacity of the floodplains influences the volume of water which leaves the river. In narrow river valleys this volume is too small to effectively reduce the peak flow. In large alluvial plains such as along the Rhine River in the Netherlands or along the Po River in Italy, flood simulations have shown discharge reductions of about one third of the pre-breach situation.

The importance of system behaviour was acknowledged before [8,9] and methods were proposed by $[10,11,12,3,4]$ to take dike failure into account in flood risk analyses. [9] studied the effect of upstream breaches on downstream flood frequencies for the Rhine River from Cologne to Rees by using a probabilistic method. They showed that the 1:5000 year discharge at location Rees (at the Dutch-German border) is lowered from $17,500 \mathrm{~m} 3 / \mathrm{s}$ to about $15,500 \mathrm{~m} 3 / \mathrm{s}$ if breaches are taken into account. The effect of this reduction on flood risks was not studied.

[10] and [12] calculated the effects of breaches on flood risks for one dike ring in a probabilisticdeterministic framework which was computationally very time-consuming and therefore not feasible to apply on larger scales [3].

[4] developed a method to assess the effects of breaches of flood hazards and applied it on the Elbe River. They produced probabilistic flood hazard maps for 4 'hazard scenarios' (for recurrence times of 100, 200,
500, and 1000 years) and for different flood hazard parameters. [11] applied this method to analyse the effects of a flood detention area and to do so, added damage assessment to the method. They studied the uncertainties in damage per 'hazard scenario' by taking into account the uncertainties in flood depths and by calculating damage with different damage assessment models. Finally, they integrated the four hazard scenario outcomes into one risk figure. They did not sample from the whole discharge probability density function. Their approach is valuable for river areas where 'the once in 1000 year' event is clearly identifiable. In areas where the once in 1000 year hazard scenario differs from place to place, it is less feasible. In the Rhine delta for example, in the upstream part the once in 1000 year flood level will be related to the once in 1000 year discharge coming from the upper river, whereas near the coast it will be related to the one in 1000 year storm surge level, while in the transition area between the tidal and non-tidal area events such as the $1 / 10$ year storm surge level in combination with a $1 / 10$ year river discharge might produce the 1/1000 year flood level. For delta areas thus a different approach is needed which considers the whole range of possible storm surge levels and river discharges in an integrated way.

Such an approach was developed by [3] who took into account the effect of failure of embankments into flood risk analyses for a large river delta. Their method enables the consideration of flood protection standards, failure mechanisms, storage capacity and impacts.

In this paper, we apply the method of [3] in order to assess the effects of hydrodynamic interdependencies on the flood risks of the lower Rhine River and discuss how this knowledge could support flood risk management decisions.

The paper starts with a brief description of the Rhine River area and the method used to assess hydrodynamic interdependencies, then shows the effects of hydrodynamic system behaviour on failure probabilities and risks, and finally discusses the potential consequences for flood risk management decisions.

\section{The Lower Rhine River}

This paper focuses on the Dutch part of the Lower Rhine River, from the Dutch-German border until the North Sea and Lake IJssel (see figure 1). The embankments in this area are designed to protect against flood levels with a probability of $1 / 1250$ to $1 / 10.000$ a year, according to the Dutch Water Act. However, not all embankments meet these requirements yet, whereas some are much stronger than required. New insights on failure mechanisms and strength of embankments has resulted in failure probability estimates ranging from $1 / 100$ per year to less than once in a million years [13], as shown in figure 2. The tidal stretches of the river area are also protected against storm surges by the Maeslant Barrier, the operation reliability of which is hence important.

The probabilities of extreme water levels in the eastern part are determined by the probabilities of 
extreme river discharges, in the most western part the probability of extreme flood levels is dominated by the probability of storm surges and failure of the Storm Surge Barrier. In the transition area both river discharges and storm surges are important. Hydrodynamic interdependencies are expected to be most relevant for the non-tidal and transition zones, since their breaches will reduce the river discharge.

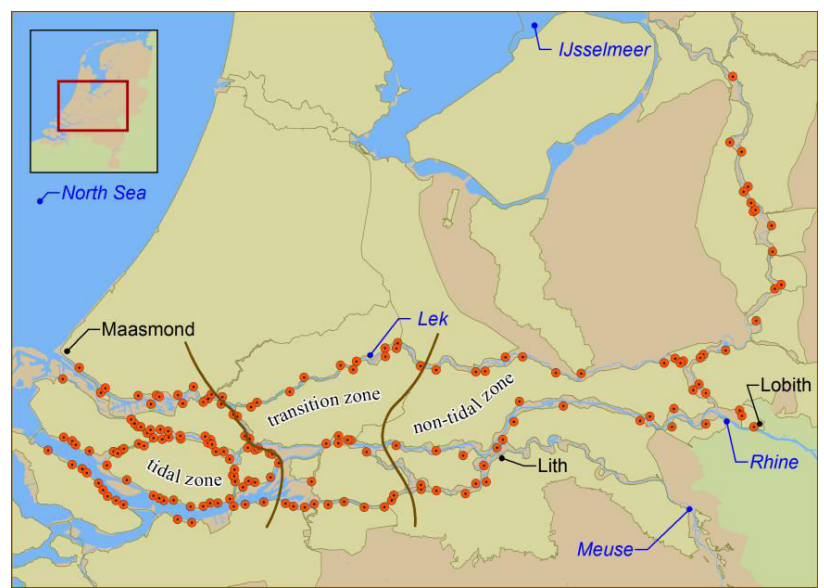

Figure 1. Map of the case study areas with the boundaries of the studied area (Lobith, Lith, IJsselmeer, North Sea), the three zones dominated by different flood types (tidal zone, non-tidal zone and transition zone, and the potential breach locations (red dots) (source: [3]).

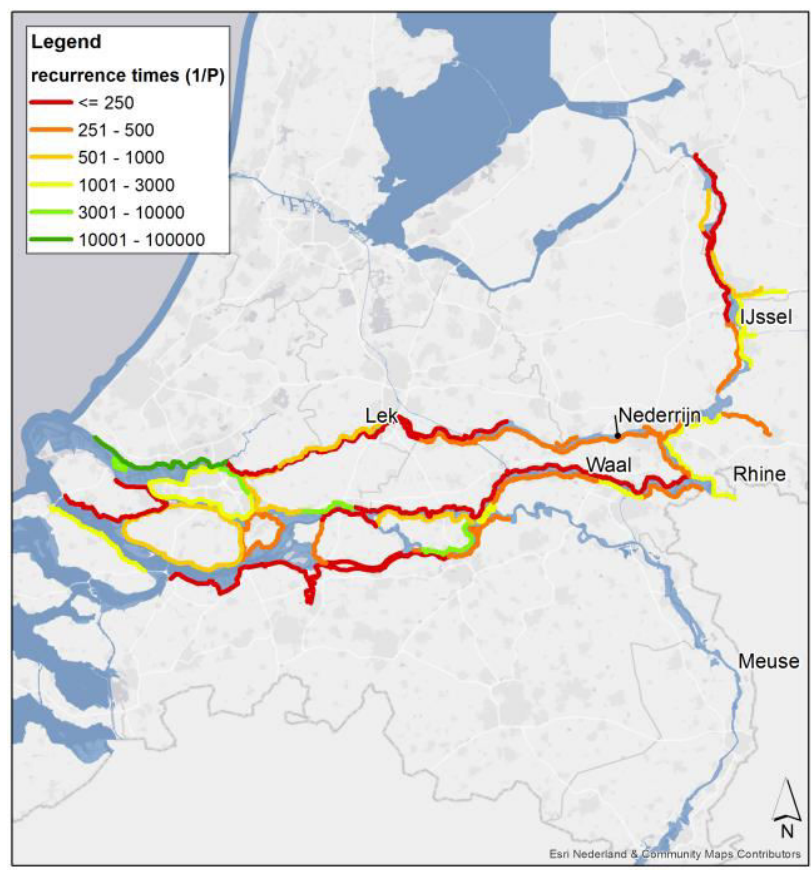

Figure 2. The current failure probabilities (adapted from [13])

\section{Flood risk analysis method}

\subsection{Overview of the method}

A probabilistic modelling framework was developed with the aim to quantify societal fatality risks for large river deltas. Details of the model are described in [3 and 14]. Below, a brief summary is provided.

The computation of flood risks involves dealing with multiple sources of uncertainty. In our framework, uncertainties in the hydraulic loads, the strength of the flood defences, the evacuation response and the resulting number of flood fatalities from a breach are all taken into account. The different sources of uncertainty are described with probability density functions, which are input for the framework. The framework consists of the following components (see figure 3):

1. Generation of synthetic events characterized by load, strength and response variables;

2. Hydrodynamic modelling of the sampled events; and

3. Translation of the results to fatality numbers per event.

The outcomes per event are used to calculate FN-curves: curves which provide the probability of events with more than $\mathrm{N}$ fatalities. The framework can, of course, also be easily adapted to allow the construction of flood loss curves indicating the probability of events with more than $\mathrm{N}$ euros of damage.

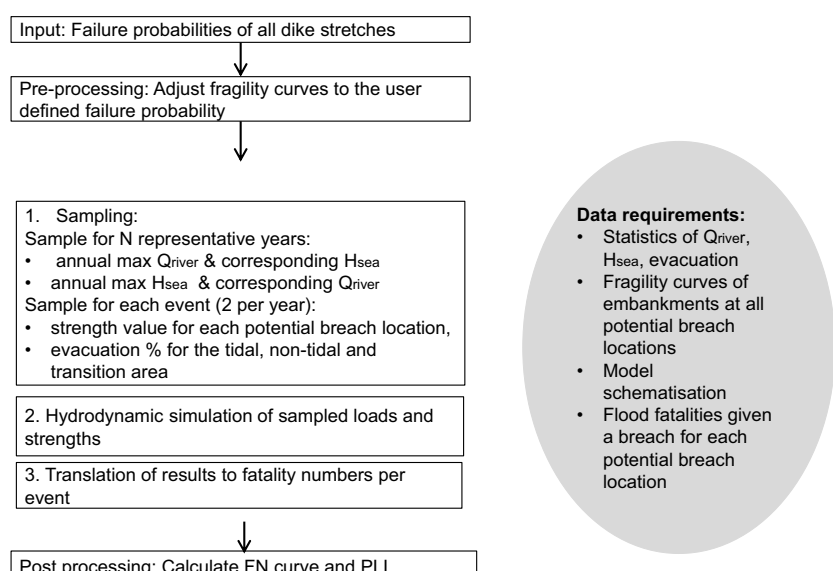

Figure 3. Schematic overview of the probabilistic risk assessment method for river deltas (adapted from [3])

\subsection{Component 1: Sampling events}

The generation of events (component 1) starts with sampling of hydraulic load variables like river discharge and sea water level from derived distribution functions.

Subsequently, the strength of the flood defences is sampled from fragility curves for a finite number of potential breach locations. Breaching of flood defences can potentially occur anywhere in the system. The framework, however, requires a finite set of potential breach locations. These breach locations are selected in such a way that all relevant flooding scenarios are captured. For this purpose, the system of flood defences 
is subdivided into several stretches, based on the criterion that flood consequences are approximately the same for breaches at any location within a single stretch. For each stretch, a single representative potential breach location was selected.

For each potential breach location, fragility curves are derived for all relevant failure mechanisms based on characteristics of the flood defences. Three failure mechanisms are considered that are known to be dominant for riverine flood defences: "erosion of the inner slope", "piping" and "slope instability". This means for each simulated event and each location that 3 flood levels are sampled from the fragility curves, representing the water levels at which the flood defence will breach due to the corresponding failure mechanism. The lowest of the 3 breaching levels is the water level at which the flood defence is supposed breach. The final step in component 1 consists of sampling a success rate of the evacuation response, which is used later to calculate the expected number of fatalities in a flood event.

\subsection{Component 2: Simulating events}

Each event is simulated with a hydrodynamic model to calculate the hydraulic consequences on all locations of breaches. The sampled hydraulic load variables like river discharge and sea water level serve as boundary conditions for these simulations. The sampled dike strength values (water levels at which breaching will occur) from the fragility curves are also input to the hydrodynamic modelling. At each simulation time step, locations are identified for which the water level exceeds the breaching level. At the moment that happens, the formation of a breach is assumed and hence simulated and water is abstracted from the river. This leads to a lowering of downstream water levels as well as flooding of the protected polders. Consequently, the framework is thus able to take the reducing effect of breaching on downstream water levels and flood probabilities into account.

\subsection{Component 3: Calculating impacts and deriving the $\mathrm{FN}$ curve}

In the post-processing procedure, the expected number of fatalities in the simulated events is derived from parameters such as the flooded area, the number of inhabitants and the evacuation success rate. These numbers are used to construct FN-curves that show frequencies of exceedance of (large) numbers of flood fatalities.

\section{Results}

We show the effects of hydrodynamic interdependencies by first providing the results for one event from the Monte Carlo analysis and then discuss the results of the whole set. We explain the effects of hydrodynamic interdependencies on water levels, failure probabilities, number of breaches, and flood risk.

\subsection{Results for one event}

We show the results for one event with a Rhine River discharge at Lobith of $15,232 \mathrm{~m}^{3} / \mathrm{s}$, a Meuse River discharge at Lith of $2,460 \mathrm{~m}^{3} / \mathrm{s}$ and a sea water level of $2.5 \mathrm{~m}$ above msl and a set of embankment strength values for each potential breach location (sampled from the fragility curves). This event contains an extreme Rhine discharge, (higher than ever recorded but less than the design discharge) and high, but not exceptional Meuse discharge and a sea level with a return period of approximately 1.5 years. This scenario was simulated twice: once with and once without taking into account hydrodynamic interdependencies.

Figure 4 shows the breach locations found in both cases. If the interdependencies are considered only 6 breaches occur, whereas if they are not, 34 breaches are expected to occur and flood impacts are much larger.

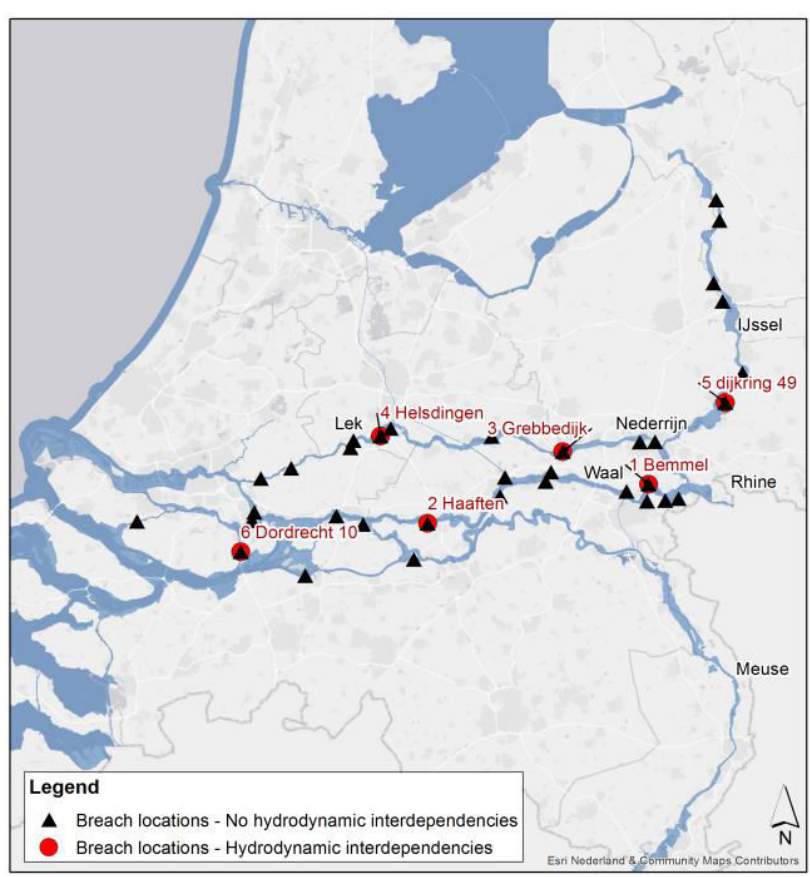

Figure 4. Breach locations for example scenario 1 assessed with and without taking into account hydrodynamic interdependencies.

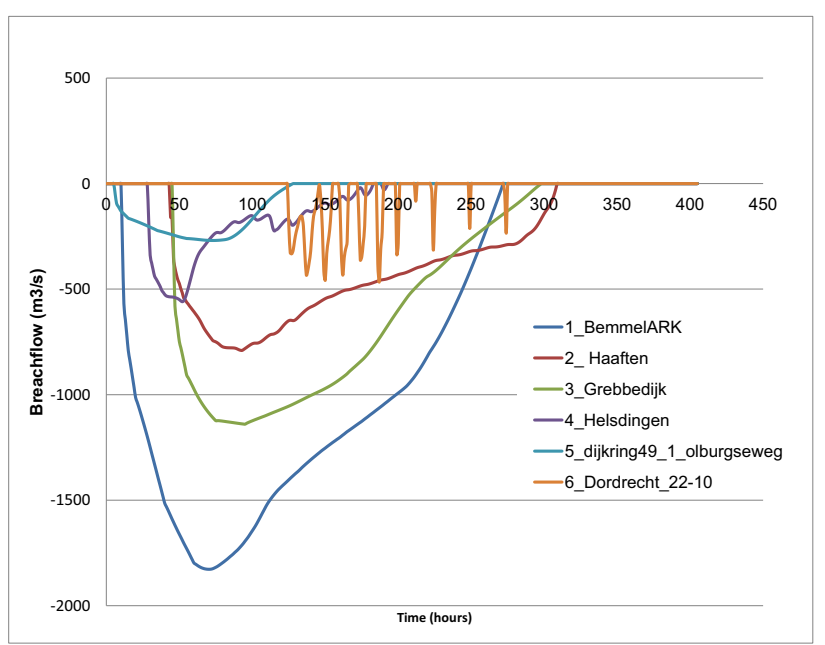

Figure 5. Discharges through the breaches over time 
The breach flows calculated for the situation in which hydrodynamic interdependencies are considered are visualised in figure 5 and the corresponding maximum discharge along the Waal River (the southern Rhine branch) is shown in figure 6. The large breach at Bemmel (location 1) causes an increase in discharge just upstream of the breach and a large decrease downstream of the breach. The second breach along this branch at Haaften (location 2), lowers the discharge on the Waal branch even further.

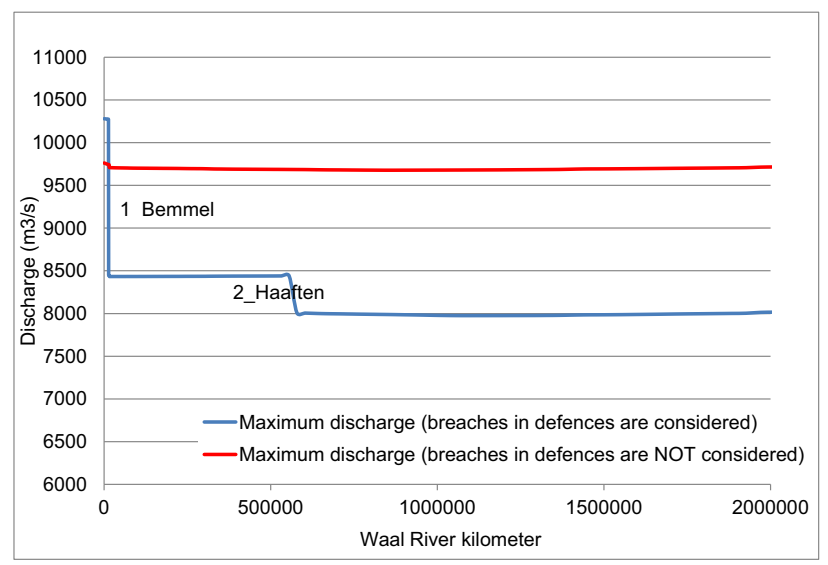

Figure 6. Waal maximum discharges in the example event

The resulting water levels from the simulations with and without taking into account hydrodynamic interdependencies differ most along the Waal River downstream of Bemmel (location 1). Also downstream of the breaches at the Grebbedijk (location 3) and on the IJsel River (location 5) water levels are lowered significantly. In the western tidal part of the area and along the Meuse River differences are negligible.

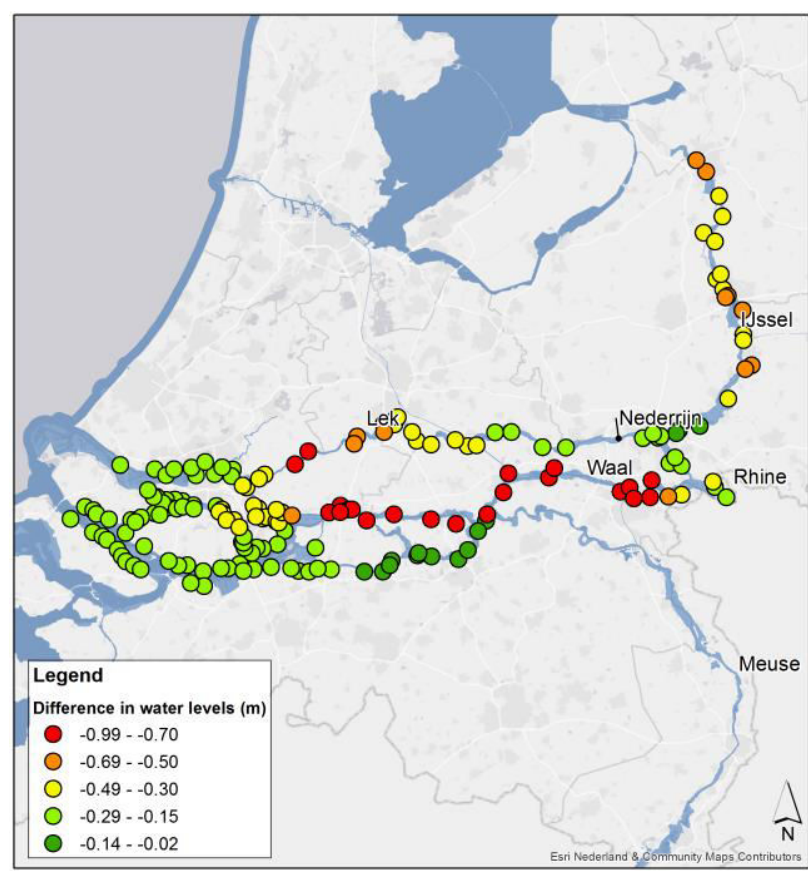

Figure 7. Maximum water levels with and without taking into account hydrodynamic interdependencies

\subsection{Consequences for the flood risk of the system as a whole}

The effects of taking into account hydrodynamic interdependencies are visualised for water levels, water level exceedance probabilities, failure probabilities and risks. The effect of hydrodynamic interdependencies on water levels is illustrated by figure 8 . Figure 8 shows that hydrodynamic interdependencies are less relevant for upstream locations with relatively weak embankments (Bemmel) than for downstream locations (Gorinchem) with stronger embankments. The large effect at Gorinchem is not only related to its downstream location, but also to the embankment strength in comparison to that of the embankments on the opposite bank of the river and upstream. Figure 8 shows that in Bemmel, Gorinchem and Amerongen water levels do not increase with increasing Rhine River discharge anymore above a value of about $12,000 \mathrm{~m}^{3} / \mathrm{s}$ at Lobith.

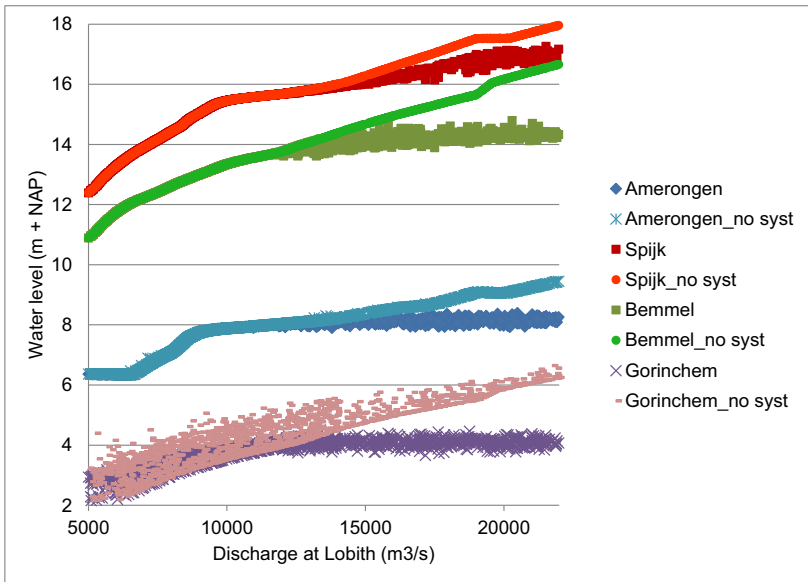

Figure 8. Relation between maximum discharges at Lobith and maximum water levels at various locations assessed with and without taking hydrodynamic interdependencies into account $($ without $=$ no syst $)$

The effects on failure probabilities are visualised in figure 9. This figure shows that at locations where the embankments upstream, or across the river are less strong, the effects of taking into account interdependencies on failure probabilities is more pronounced. Along the Waal River for example, the northern embankment is less strong than the southern one, which means the effects of interdependencies are clearly noticeable for the southern embankment, but less for the northern one. The effects on the western part of the Betuwe area (along the downstream stretch of the Waal River) are also larger than elsewhere. These effects are caused by the larger failure probabilities of the northern embankment along the upstream part of the Waal River (the eastern part of the Betuwe area). In the tidal river area the effect of hydrodynamic interdependencies is limited. The analysis shows that the effects are not fully determined by the location (upstream or downstream), but strongly depend on the differences in failure probabilities between the embankment sections. 


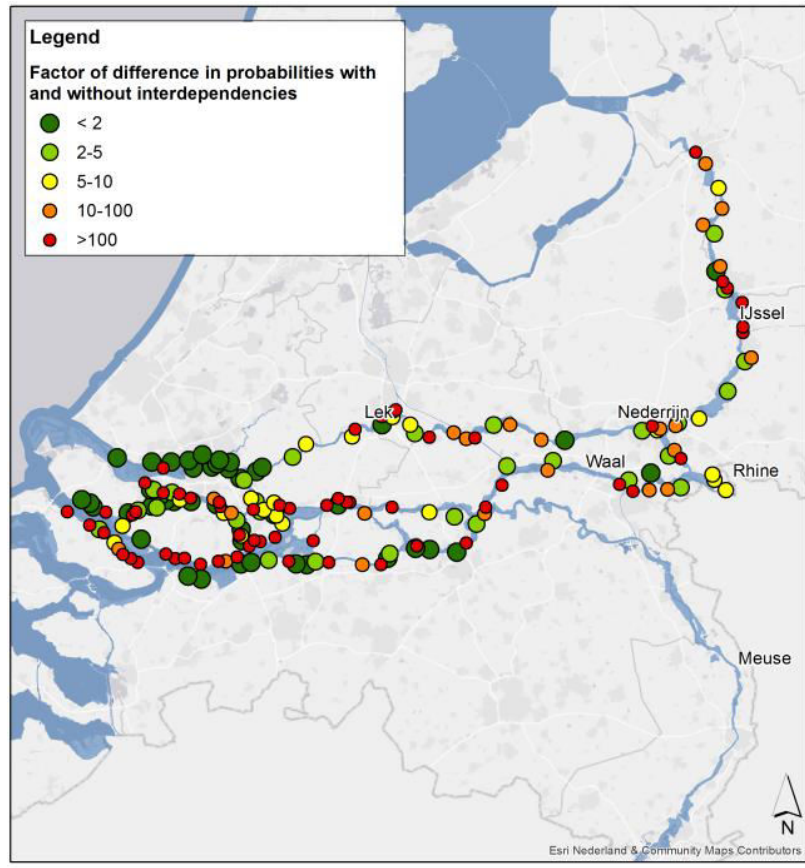

Figure 9. Factor of difference in failure probability: probability of failure calculated without considering hydrodynamic interdependencies divided by the one based on calculation with taking into account these dependencies.

By taking into account hydrodynamic interdependencies a more realistic estimate of the likely number of breaches due to extreme river flood waves can be calculated. Figure 10 shows the number of breaches as a function of the discharge with and without taking into account hydrodynamic interdependencies and figure 11 shows the probability of exceedance of $\mathrm{N}$ breaches. Both only consider breaches in the non-tidal zone (see figure 1 for its location).

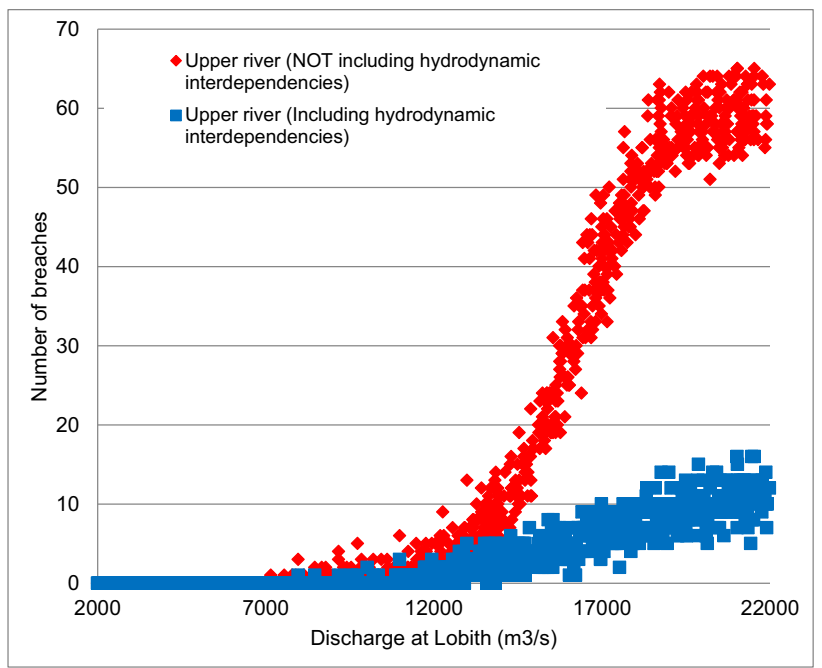

Figure 10. Number of breaches in the non-tidal river part as a function of the discharge at Lobith (with and without taking into account hydrodynamic interdependencies).

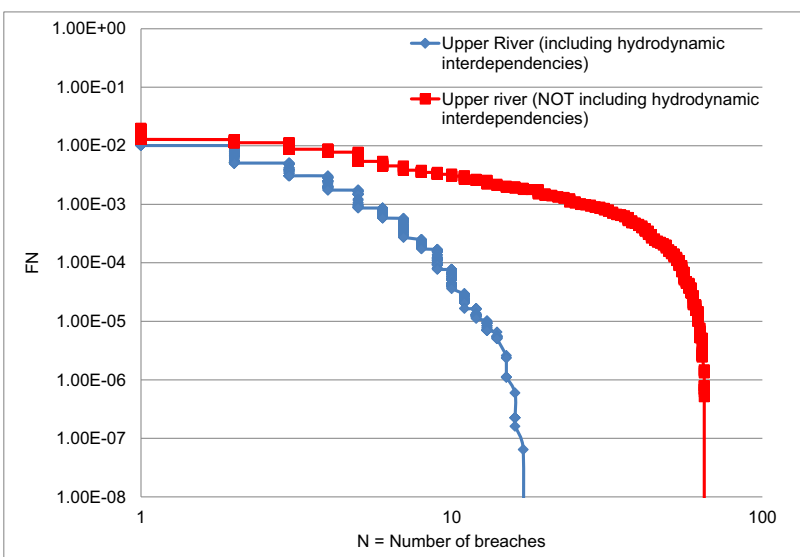

Figure 11. Annual probability of exceedance of $\mathrm{N}$ breaches in the non-tidal river area (with and without taking into account hydrodynamic interdependencies).

Figure 12 shows the effect of hydrodynamic interdependencies on the flood risk of the whole system in an FN curve. This curve gives the annual probability of an event with $\mathrm{N}$ or more fatalities. The curves based on simulations with and without interdependencies differ especially for very rare extreme events, primarily because the number of breaches is significantly less.

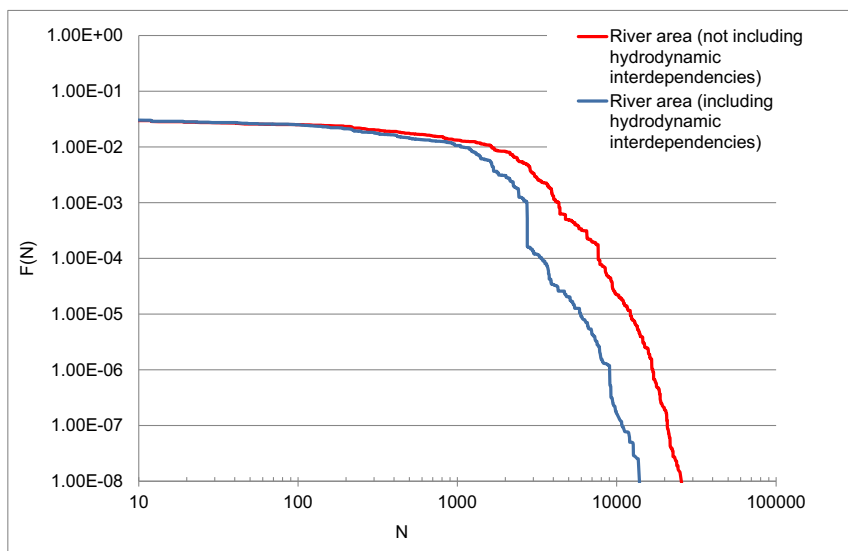

Figure 12. FN curve with and without taking into account hydrodynamic interdependencies (the effect of breaches on failure probabilities of other locations)

\section{Discussion}

This section discusses the implications of taking into account hydrodynamic interdependencies on flood risk assessments (5.1), the implication of these new insights for flood risk management along the Lower Rhine River (5.2) and what lessons can be drawn for risk analysis in other lowland river settings with flood protection infrastructure in place (5.3).

\subsection{The effect of hydrodynamic interdependencies}

The results presented in chapter 4 demonstrate the effects of hydrodynamic system behaviour for the Lower Rhine River in the current situation. Currently, new protection standards are being considered which will 
require reinforcements and perhaps the heightening of embankments, thus influencing the failure probabilities of stretches and also the hydrodynamic interdependencies. However, the most relevant factors, the method to quantify the effect and the general insights will still stand. Insights such as that upstream locations with larger failure probabilities will reduce the breaching probabilities and flood risks of downstream locations and the notion that hydrodynamic interdependencies thus reduce overall flood risks in lowland rivers with protected areas on one or either side, remain valid.

Another important issue to address is that the effect of hydrodynamic interdependencies on flood risks strongly depends on flood impacts and spatial differences between impacted areas. If areas with weaker embankments have small flood impacts, and areas with stronger embankments face larger impacts in case of flooding, the positive effect of hydrodynamic interdependencies on flood risks is larger than if impacts are homogenously distributed. The results in chapter 4 provide the effects in case the impacts are distributed as they are at present in the Netherlands, but this represents just a base case.

The method applied allows consideration of uncertainties in loads, strengths, and evacuation success. However, it does not fully capture the effect of the moment of breaching. In the method used, embankments fail when the water level exceeds the breaching level. This will happen before or at the peak of the river flood wave. In reality failure may also occur after the peak of the flood wave has passed. If that happens, the water level and risk reducing effect of the breach on downstream locations is less. This effect could be taken into account if the fragility curves relating water levels to failure probabilities would be replaced by twodimensional curves which would also comprise the duration of exceedance of water levels [10].

\subsection{The relevance for flood risk management along the Lower Rhine River}

In the Netherlands flood risks are usually assessed per embankment section, or per dike ring area without taking into account hydrodynamic interdependencies due to breaches within the country. However, the Netherlands counts on discharge reduction due to flooding in Germany. The maximum discharge coming from Germany is considered to be approximately $18,000 \mathrm{~m}^{3} / \mathrm{s}$ $[15,16]$. The discharge-reducing effect of flooding upstream of the German-Dutch border is thus taken into account, but the effect of floods downstream of the border is neglected.

For the current discussion on new protection standards the effects of hydrodynamic system behaviour were taken into account to help answer the question how likely large disrupting floods could be. To this end, the probability of events with more than $\mathrm{N}$ fatalities was determined and assessed in relation to a proposed level of tolerability. Where needed flood protection standards were then raised in order to lower the probabilities below the tolerable level. The hydrodynamic interdependencies were especially helpful in establishing the number of potential breach locations in one event.

So far, most risk analyses in the Netherlands have commonly neglected the effect of interdependencies for two reasons: Firstly, the effect is uncertain and hence difficult to assess and secondly, if it would be taken into account, decision making would be complicated because each decision on a measure would influence the effect of many other measures.

The strength of embankments is uncertain indeed, which means that no one can guarantee that embankments with a larger failure probability will fail and 'protect' sections with a smaller failure probability. However, as we have shown, it is possible to take hydrodynamic interdependencies into account while recognizing the uncertainty in its effect.

If hydrodynamic interdependencies are taken into account, then the decision to strengthen an embankment in an upstream stretch may require that also embankments on the opposite bank and downstream be strengthened since their probability of failure will be increased. This makes decision-making more complicated. In contrast, raising them immediately, while neglecting that upstream embankment failures reduce downstream failure probabilities, would mean that taxpayers' money would not be invested efficiently.

For questions related to impacts per flood event, insight into the number of potential breaches is crucial. The insurance industry may want to know if and how much re-insurance is needed in order to prevent them going bankrupt due to extreme events affecting multiple areas, governments desire to know if societal disruption may occur due to large flood events or whether better protection is required, and emergency management planning must be based on realistic scenarios and not on a worst case. With our current model we have now been able to simulate what we earlier found as empirical evidence, namely that the total number of breaches during the largest ever recorded 1926 flood was effectively limited due to upstream breaching [17].

The main reason to include hydrodynamic interdependencies is that it allows optimization for the basin as a whole instead of for individual locations. Local optimizations take into account only local impacts and local costs of dike strengthening. The increase of flood probabilities and risk elsewhere along the river is not taken into account in such analyses. Optimizing strategies from a systems perspective requires more sophisticated modelling and optimization methods, however. Such system-based optimization could also comprise flood management measures which have an effect beyond their location, such as making room for rivers, e.g. by dike relocation or floodways, or in the form of storage in offstream detention areas.

\subsection{Relevance for other river systems}

The effect of hydrodynamic interdependencies is not only relevant for the Rhine River, but also for other lowland rivers with flood protection infrastructure in place. These interdependencies are already taken into 
consideration in areas with detention storage areas or floodways (e.g. the Madrid floodway in the Mississippi as discussed in [5]), in decisions about purposefully flooding areas in order to lower water levels elsewhere (which has been discussed in the past for the Po River in Italy, for the Elbe River in in Germany, and also in the Netherlands; and which has been successfully practiced along the Mississippi River).

If (protected) areas are studied in isolation, this may result in inefficient strategies, e.g. when risk is transferred to more vulnerable downstream areas as a consequence of upstream measures, or when insurance premiums are based on an overestimate of the possible consequences per event.

\subsection{Next steps}

Because the effects of hydrodynamic interactions on flood risks are significant and knowledge on those effects helps decision makers to improve making decisions on insurance, emergency management and on flood protection standards, their consideration in flood risk analyses must be enhanced.

In support of this, a work package of the Marie Curie project 'System Risk' will focus on these effects and three PhD students will do research on those effects and on how to use the knowledge to improve flood risk strategies. They will study the Rhine, Elbe and Po Rivers, but their methods must be applicable elsewhere also.

\section{References}

1. Jongejan, R.B., Maaskant, B. (2015). Quantifying flood risks in the Netherlands. Risk Analysis, 35(2):252-64.

2. Hall, J.W., Sayers, P.B., Dawson, R.J. (2005) National-scale assessment of current and future flood risk in England and Wales. Nat. Hazards (36) 1-2 Pp. 147-164, 2005.

3. De Bruijn, K.M., Diermanse, F.L.M., Beckers, J.V.M. (2014). An advanced method for flood risk analysis in river deltas, applied to societal flood fatality risk in the Netherlands. Nat. Hazards Earth Syst. Sci., 14, 2767-2781. doi:10.5194/nhess-142767-2014

4. Vorogushyn, S., Merz, B., Lindenschmidt, K.-E., Apel, H. (2010) A new methodology for flood hazard assessment con-sidering dike breaches. Water Resources Research 46, W08541.

5. Olson, K.R., \& Morton, L.W. (2012). The effects of 2011 Ohio and Mississippi river valley flooding on Cairo, Illinois, area. J. Soil Water Conserv. 67, 42A46A.

6. Amadio, M. (2012). Flood risk assessment in the Po River basin under a climate change scenario. Msc Thesis, Joint Master's programme in sustainable development. Ca' Foscari University \& Utrecht University. Accessible through: http://dspace.unive.it/bitstream/handle/10579/1882/8 25260-76816.pdf? sequence $=2$
7. Klerk, W.J. Kok, M., De Bruijn, K.M., Jonkman, S.N., Van Overloop, P.J.A.T.M. (2014). Influence of load interdependencies of flood defences on probabilities and risks at the Bovenrijn/Ijssel area, The Netherlands. Proceedings of the $6^{\text {th }}$ International Conference on Flood Management, September 2014, Sao Paulo, Brazil.

8. Apel, H., Thieken, A., Merz, B., Blöschl, G. (2004). Flood risk assessment and associated uncertainty. NHESS, 4, 295-308, 2004.

9. Apel, H., Merz, B., Thieken, A.H. (2009). Influence of dike breaches on flood frequency estimation. Computers \& Geosciences 35, 907-923, 2009.

10. Van Mierlo, M.C.L.M. Vrouwenvelder, A.C.W.M., Calle, E.OF., Vrijling. J.K., Jonkman, S.N., De Bruijn, K.M., Weerts, A.H. (2007). Assessment of floods risk accounting for River System Behaviour, Intl J. River Basin Manage. 5, (2), 93-104.

11. Vorogushyn, S., Lindenschmidt, K.-E., Kreibich, H., Apel, H., Merz, B. (2012): Analysis of a detention basin impact on dike failure probabilities and flood risk for a channel-dike-floodplain system along the river Elbe, Germany. - Journal of Hydrology, 436-437, 120-131. DOI: 10.1016/j.jhydrol.2012.03.006

12. Vrouwenvelder A.C.W.M. et al. (2010). Risk analyis for flood protection systems. Main report, TNO \& Deltares, Delft, the Netherlands, 2010.

13. Deelprogramma Veiligheid. (2014). Technischinhoudelijke uitwerking van eisen aan primaire waterkeringen (DPV 2.2). WVL \& Deltares, Nederland (In Dutch).

14. Diermanse, F.L.M., De Bruijn, K.M. and Beckers, J.: Importance sampling for efficient modelling of hydraulic loads in flood risk analysis. Stoch Environ Res Risk Assess. DOI 10.1007/s00477-014-0921-4

15. Hegnauer, M., Kwadijk, J., Klijn, F. (2015). The plausibility of extreme high discharges in the river Rhine. Project 1220042-004, Deltares, Delft. The Netherlands.

16. Sperna Weiland, F.C., Hegnauer, M., Van den Boogaard, H., Buiteveld, H., Lammersen, R. and Beersma, J. (2016) Implications of CMIP5 derived climate scenarios for discharge extremes of the Rhine, submitted to $4^{\text {th }}$ IAHR Europe Congress, Liege Belgium 27-29 July 2016.

17. Ververs, M. \& F. Klijn (2004). Werken noodoverloopgebieden? Wat leert ons de overstroming van 1926? Geografie 7 (september 2004): $14-17$ 